\title{
Selection of Effective Herbal Medicines for Parkinson's Disease Based on the Text Mining of the Classical Korean Medical Literature Donguibogam
}

\author{
Hyo Won Bae ${ }^{1}$, Tae Wook Lee ${ }^{1}$, Byung Tae Choi ${ }^{1,2,3,4}$, Hwa Kyoung Shin ${ }^{1,2,3,4}$, Young Ju Yun ${ }^{1 *}$ \\ ${ }^{1}$ Department of Korean Medicine, School of Korean Medicine, Pusan National University \\ ${ }^{2}$ Department of Korean Medical Science, School of Korean Medicine, Pusan National University \\ ${ }^{3}$ Korean Medical Science Research Centre for Healthy-Ageing, Pusan National University \\ ${ }^{4}$ Graduate Training Programme of Korean Medical Therapeutics for Healthy-Ageing, Pusan National University
}

\begin{abstract}
Objectives: The prevalence of Parkinson's disease is on an upward trend along with an increase in the aging population but there is no available treatment that halts the progression of neurodegeneration. This study reports a numerical analysis on Donguibogam and suggests novel herbal drugs, which have never been researched before but found to be deemed effective in this study.

Methods: Referring to 71 Korean medicine symptom terms that represent the symptoms of Parkinson's disease, 4170 prescriptions described in Donguibogam were classified into two groups based on whether their main effects were effective for Parkinson's disease or not. Comparing the two groups, the chi-square test was performed to select statistically significant herbs, while the t-test, Wilcoxon test, and descriptive statistics were performed to determine the appropriate dose.

Results: One hundred and twenty-seven prescriptions effective for Parkinson's disease were identified. The chi-square test determined 17 herbs that are effective for symptomatic treatment. Among the medicinal herbs, the authors suggest Osterici seu Notopterygii Radix et Rhizoma, Ephedrae Herba, Aconiti Tuber, Myrrha, Sinomeni Caulis et Rhizoma, and Aconiti Kusnezoffii Tuber as herbal candidates that have never been studied for Parkinson's disease. Through the statistical tests, it was judged that the mean value of the dose of the entire prescription was the appropriate dose for each herb.

Conclusions: Seventeen herbs were selected for Parkinson's disease and the appropriate daily dose were calculated. Furthermore, this study presented a new process that applies a statistical method to traditional medical literature and preselecting herbs deemed effective for specific diseases.
\end{abstract}

$\overline{K e y ~ W o r d s}$ : Dongeuibogam, Herbal medicine, Parkinson's disease

\section{Introduction}

Parkinson's disease (PD) is a neurodegenerative disorder whose aetiology is not clearly identified. Medication therapy and deep brain stimulation are currently used to treat $\mathrm{PD}$, but there is no available treatment that halts or decelerates the progression of neurodegeneration ${ }^{1)}$. Levodopa, a prodrug to dopamine, and dopamine agonists are the core of medication therapy, and there are additional drug adjuvants to levodopa, including amantadine, $\beta$-blockers, catechol-O-methyl transferase

\footnotetext{
- Received : 18 August 2021

- Revised : 13 September 2021

- Accepted : 5 November 2021

- Correspondence to: Young Ju Yun

School of Korean Medicine, Pusan National University, Yangsan 50612, Republic of Korea

Tel : +82-55-360-5955, Fax : +82-55-360-5509, E-mail : mdkmdyun@pusan.ac.kr
} 
inhibitors (e.g., tolcapone, entacapone) and anticholinergic drugs ${ }^{2,3,4)}$. Levodopa is primarily aimed at symptomatic treatment and does not stop the progression of PD. In addition, the side effects of levodopa caused by administrative delays and the long-term risk of motor complications conclusively aggravate the patient's quality of life $^{5,6)}$. Deep brain stimulation only offers symptomatic relief and has disadvantages, including side effects and additional battery replacement surgery when the battery runs out ${ }^{7}$.

In response to the growing demand for alternative treatment of Parkinson's disease, numerous studies have been conducted to discover the therapeutic potential of medicinal herbs for PD and the National Institute for Korean Medicine Development (NIKOM) published the Clinical Practice Guideline for Parkinson's Disease in $2020^{8,9,10,11)}$.

In general, the selection of candidate substances is made by paying attention to the well-known efficacy of the drugs or the specific main effect of the prescription. The main effect is the concept that a prescription mainly targets treatment with a synergistic effect of its constituent herbs according to the principle of traditional Korean medicine and is described in the form of Korean medicine symptom terms. This approach could yield guaranteed results but sometimes come up with limited vision on finding novel candidate substances. Thus, this study aims to provide a distinguished basis for finding effective herbs for PD by numerically analysing Donguibogam.

Donguibogam is a Korean classical medicinal literature completed in 1610, a thorough compilation, and an updated version of traditional medicine at the time ${ }^{12)}$. In July 2009, UNESCO decided to add Donguibogam to the cultural heritage list because of its significance and contribution to the development of traditional medicine ${ }^{13)}$. Donguibogam is a well-organised medical encyclopaedia which includes various medical knowledge of prescriptions, main effects, compositions of herbs, dosage, and other details. For this reason, this literature is worth studying as it is easy to obtain information through data analysis.

There is a previous study that discovered herbs deemed effective for PD in light of this statistical approach to Donguibogam ${ }^{14)}$. However, there are constraints on the generalisability of the findings because the study only focused on rigidity among multiple symptoms of PD and the analysis was performed only to select frequently prescribed herbs for rigidity. Although PD symptoms are different for different people, diverse symptoms generally appear simultaneously.

The main symptoms of PD are bradykinesia, rigidity, and tremor. Also, various other motor and non-motor symptoms may appear ${ }^{15)}$. Among the symptoms described on Donguibogam, this research targeted the symptoms that can be classified into main and other motor-related symptoms. The authors conducted a fresh approach to analyse Donguibogam with statistical techniques. The prescriptions described in Donguibogam were classified into two groups based on whether their main effects were efficacious for Parkinson's disease or not. The authors compared the prescription frequency of the herbs in the two groups and then screened the medicinal herbs according to statistical significance. The chi-square test, t-test, and Wilcoxon test were used. 
Besides, the authors suggest a list of herbal candidates deemed effective for PD for future experiments and an appropriate dosage range for them.

\section{Materials and Methods}

\section{Standardisation of Symptom Terms}

To identify the Donguibogam prescriptions deemed potentially effective for PD, Korean medicine symptom terms corresponding to $\mathrm{PD}$ were defined according to a previous study. The previous study targeted 7,443 symptom terms of Donguibogam text data provided by the Korean Intellectual Property Office (KIPO). In this study, specialists made use of the data and carried out the screening process. The specialists, consisting of one professor of Korean Medical Classics department and three graduate students majoring in Korean medicine, identified the meaning of every single term described in Donguibogam and selected 101 symptom terms in the first step. Duplicate terms were eliminated in the second step for significant results. One double-licensed Doctor of Medicine and Korean Medicine (M.D. and K.M.D.) and two life science professors advised this research ${ }^{16}$.

Korean medicine symptom terms matched with PD:

1) tremor: chì zòng(疶疭), jū luán(拘攣), jīngǔ juăn(juăn， quán) luán(筋骨卷(捲，拳)攣)), jīngŭ luán(luán) tòng(筋骨攣(攣)痛), jīn luán(筋攣), jīn tì(筋惕), shǒu zhèn(手振), yang shǒu(揚手), luán ji(攣急), luán bì(攣庳), ròu rún(肉眼), zhàn diào (戰掉), zhàn yáo(戰搖), zhì zú(擲足), chè tòng(掣
痛), chōu chè(抽掣), fēng chù(風搐), chù nuò(搐 搦)

2) rigidity: qiáng jí(强急), qiáng zhí(强直), qiáng tòng(强痛), jū jí(拘急), jīn jí(筋急), shēn qiáng(身 强), luán jí(攣急), yāo jí qiáng(腰脊强), xiàng qiáng(項强)

3) other motor disturbance symptoms: jiān bēi shěn zhòng(肩背沈重), gǔ jiē téng tòng(骨節疼痛), gǔ zhòng(骨重), gǔ tòng(骨痛), jīn bì(筋痺), má mù(麻木), má bì(麻痺), bàn shēn bù shōu(牛身不 收), bù lü jiān kǔ(步履艱苦), bù suí(不隨), bù rén (不仁), bù suì(不遂), jīn gǔ téng tòng(筋骨疼痛), bèi xīn yī diăn tòng(背心一點痛), bēi tòng(背痛), bì tòng(痺痛), sì zhī juàn dài(四肢倦㤐), sì zhī wú li(四肢無力), sì zhī huăn ruò(四肢緩弱), shēn bì(身 痺), yāo bēi suān téng(腰背酸疼), yāo bēi shí tòng(腰背時痛), yāo jǐ tòng(腰脊痛), lì fá(力乏), yāo jiăo wú lì(腰脚無力), yāo tuǐ shěn zhòng(腰腿 沈重), wěi(瘘), zhū fēng(諸風), zhōu bì(周痺), zhōng fēng yī qiè zhū zhèng(中風一切諸證), zú xī tòng(足滕痛), zú ruò(足弱), zhī jié tòng(肢節痛), zhī tǐ téng tòng(肢體疼痛), duǒ yè(嚲曳), dă yè(打 曳), tān huàn(瘔㾑), fēng bì(風痺), fēng ji(風疾), xièyì(解㑊), zhī tǐ dài duò(肢體怠惰), sì zhī shěn zhòng(四肢沈重), piān kū(偏枯), xiàng jīn tòng(項 筋痛)

\section{Data Cleansing and Standardisation}

A database was built using the following three steps. First, a data cleansing process was performed for all 4557 prescriptions on Donguibogam, the classical literature of traditional Korean medicine. Ninety-three prescriptions were excluded due to the omission of the main effect. A total of 294 prescriptions were excluded due to the omission of composition information. With this process, 


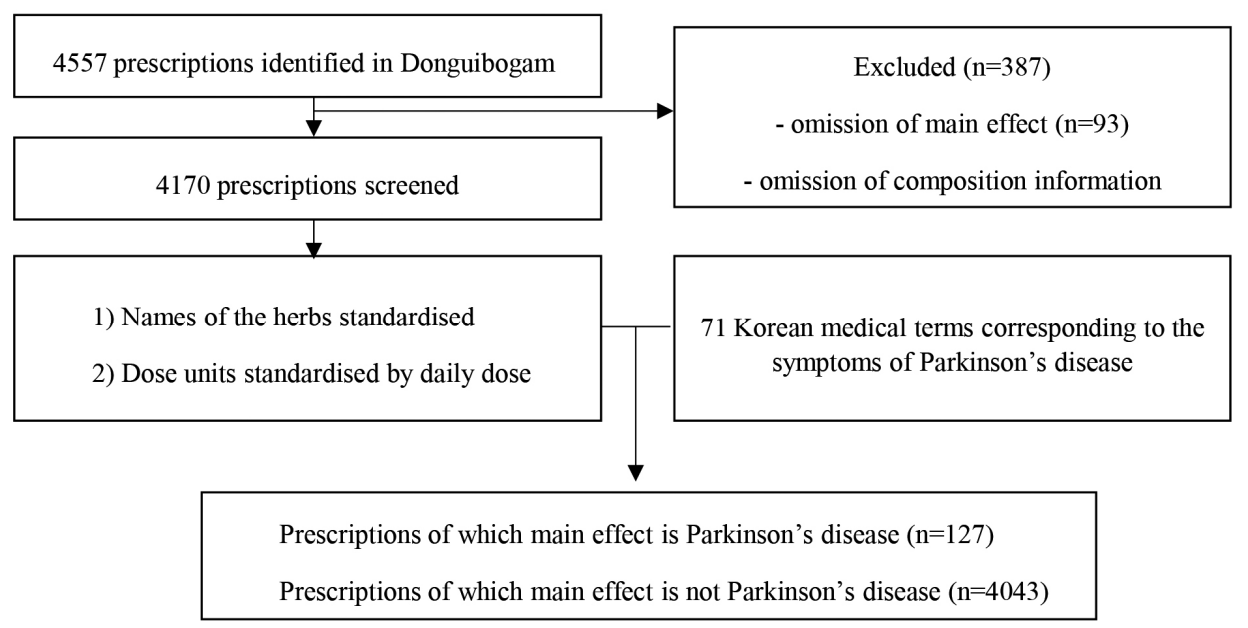

Fig. 1. The flow chart of creating and standardising basic data for analysis

4170 prescriptions were organised in the database. Second, medicinal herbs with synonymous names and sobriquets were unified under one name that is the most widely used. Third, dose units were standardised by 1-day dose when dose units of prescriptions described in the literature were different (e.g., single-dose, 1-day dose, or 10-day dose). The authors then applied 71 traditional Korean medicine symptom terms identified above to the database and 127 prescriptions, in which the main effect was identified as PD symptoms (Figure 1).

\section{Chi-square test for selecting effective medicinal herbs}

All prescriptions were grouped based on whether their main effect was for symptoms of $\mathrm{PD}$, and the groups were named 'a group of prescriptions for PD' and 'a group of prescriptions not for PD.' The prescription frequency was identified by counting how often each of the 201 herbs appeared in 127 prescriptions for PD. And 40 herbs that appeared in more than $5 \%$ of the total prescriptions were selected. The $5 \%$ criterion is an arbitrary point to obtain sufficient prescription frequency for the following statistical analysis. Next, the prescription frequency of the candidate herbs not used for PD was identified. A chi-square test was performed to evaluate the statistically significant differences in the prescription frequency of the candidate herbs when used in the two groups $(\mathrm{p}<0.01)$. However, in the chi-square test, Yate's continuity correction was used when the expected frequency was 5-9, and Fisher's exact test was used when the expected frequency was under 5 for more than $20 \%$ of the cells ${ }^{17)}$ (Figure 2).

\section{T-test and Wilcoxon test for determining the dose of medicinal herbs}

Selected herbs were statistically verified to 


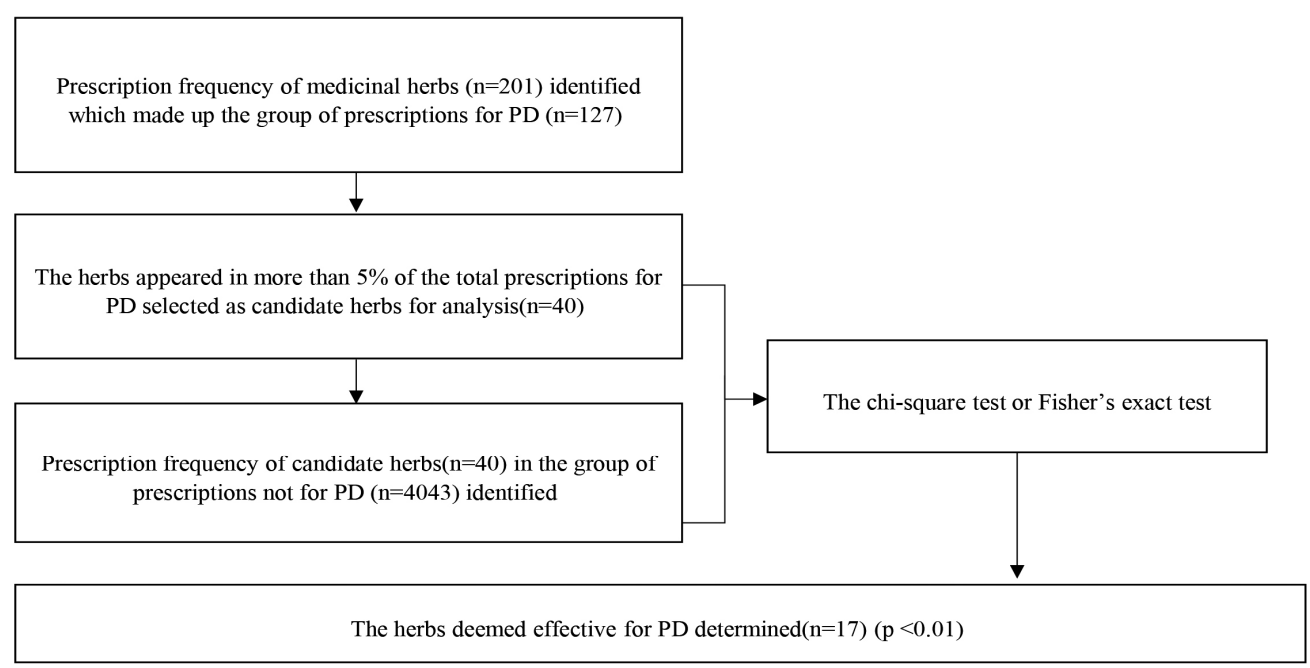

Fig. 2. The flow chart of selecting medicinal herbs deemed effective for Parkinson's disease.

determine whether there was a difference in the dose when used in the two groups. When testing the selected herbs in the two prescription groups, a t-test was performed if the data followed a normal distribution, and the sample size was large enough $(\mathrm{n}=30)$, while the Wilcoxon test, a nonparametric statistical hypothesis test, was performed if the data or the sample size did not meet the conditions $(\mathrm{p}<0.05)^{18)}$. The mean value, median value, maximum value, and minimum value were calculated to determine the recommended dose for each herb.

Only those prescriptions for which the dose regimen is clearly described in the literature, and the dosage form is brewing decoction, the most common form in traditional Korean medicine, were researched. Prescriptions of solid forms such as granules or external medicine and prescriptions for which the dose or dosing interval are not clearly described, were excluded.

Information regarding prescriptions, medicinal herbs, and main effects in Donguibogam was provided by the Korean Intellectual Property Office, the national patent office. The creation and application of the statistical methodology were done by the first author, who has a Master of Science in Statistics. Microsoft Excel 2016 and SAS version 9.4 were used for data processing and analysis.

\section{Results}

\section{Medicinal Herbs Potentially Effective for PD}

Among the total of 201 medicinal herbs used in 127 prescriptions for $\mathrm{PD}, 40$ candidate herbs with a frequency of more than $5 \%$ of the total prescriptions were selected. And 17 herbs were identified to be potentially effective for PD treatment with statistical significance $(\mathrm{p}<0.01)$ (Table 1, Table 2). In cases of Saposhnikoviae Radix, Osterici seu Notopterygii Radix et Rhizoma, 
Table 1. The herbs considered to be potentially effective for Parkinson's Disease. $(n=17)$

\begin{tabular}{lll}
\hline Botanomical name & Scientific name & Korean name \\
\hline Saposhnikoviae Radix & Saposhnikovia divaricata (Turcz.) Schischk, & Bangpung \\
Osterici seu Notopterygii Radix et Rhizoma & Ostericum koreanum Maximowicz & Kangwhal \\
Cnidii Rhizoma & Cnidium officinale Makino & Cheongung \\
Cinnamomi Ramulus & Cinnamomum cassia J.Presl & Gyeji \\
Atractylodis Rhizoma & Atractylodes lancea De Candlle & Changchul \\
Aconiti Lateralis Radix Preparata & Aconitum carmichaeli Debeaux & Buja \\
Arisaematis Rhizoma & Arisaema erubescens Schott. & Namseong \\
Araliae Continentalis Radix & Aralia continentalis Kitagawa & Dokwhal \\
Achyranthis Radix & Achyranthes japonica Nakai & Wooseul \\
Ephedrae Herba & Ephedra intermedia Schrenk et C. A. Meyer & Mahuang \\
Aconiti Tuber & Aconitum carmichaeli Debeaux & Cheono \\
Chaenomelis Fructus & Chaenomeles sinensis (Thouin) Koehne & Mogwa \\
Myrrha & Commiphora myrrha Engler & Molyak \\
Gastrodiae Rhizoma & Gastrodia elata Blume & Cheonma \\
Sinomeni Caulis et Rhizoma & Sinomenium acutum Rehder et Wilson & Bang-gi \\
Batryticatus Bombyx & Bombyx mori (Linne) & Baekkangjam \\
Aconiti Kusnezoffii Tuber & Aconitum ciliare DC. & Cho-O \\
\hline
\end{tabular}

Table 2. The result of the chi-square test and Fisher's exact test for the herbs considered to be potentially effective for Parkinson's Disease.

\begin{tabular}{|c|c|c|c|c|c|}
\hline $\begin{array}{l}\text { Analysis } \\
\text { method }\end{array}$ & Botanomical name & Korean name & $\begin{array}{c}\text { Frequency } \\
\text { rate }^{\dagger}\end{array}$ & $\chi^{2}$ & P-value \\
\hline \multirow{7}{*}{$\begin{array}{l}\text { The chi-square } \\
\text { test }\end{array}$} & Saposhnikoviae Radix & Bangpung & $31.5 \%$ & 61.407 & $<.0001$ \\
\hline & Osterici seu Notopterygii Radix et Rhizoma & Kangwhal & $26.8 \%$ & 84.608 & $<.0001$ \\
\hline & Cnidii Rhizoma & Cheongung & $26.0 \%$ & 15.524 & $<.0001$ \\
\hline & Cinnamomi Ramulus & Gyeji & $19.7 \%$ & 13.365 & 0.0003 \\
\hline & Atractylodis Rhizoma & Changchul & $18.9 \%$ & 28.258 & $<.0001$ \\
\hline & Aconiti Lateralis Radix Preparata & Buja & $11.8 \%$ & 15.057 & 0.0001 \\
\hline & Arisaematis Rhizoma & Namseong & $11.0 \%$ & 12.641 & 0.0004 \\
\hline \multirow{10}{*}{$\begin{array}{l}\text { Fisher's exact } \\
\text { test }\end{array}$} & Araliae Continentalis Radix & Dokwhal & $10.2 \%$ & & $<.0001$ \\
\hline & Achyranthis Radix & Wooseul & $9.4 \%$ & & 0.0001 \\
\hline & Ephedrae Herba & Mahuang & $8.7 \%$ & & 0.0041 \\
\hline & Aconiti Tuber & Cheono & $7.9 \%$ & & 0.0006 \\
\hline & Chaenomelis Fructus & Mogwa & $7.1 \%$ & & $<.0001$ \\
\hline & Myrrha & Molyak & $7.1 \%$ & & 0.0070 \\
\hline & Gastrodiae Rhizoma & Cheonma & $7.1 \%$ & & 0.0033 \\
\hline & Sinomeni Caulis et Rhizoma & Bang-gi & $6.3 \%$ & & 0.0002 \\
\hline & Batryticatus Bombyx & Baekkangjam & $6.3 \%$ & & 0.0057 \\
\hline & Aconiti Kusnezoffii Tuber & Cho-O & $5.5 \%$ & & 0.0001 \\
\hline
\end{tabular}

\footnotetext{
${ }^{\dagger}$ Frequency rate: The rate of how often each herb appeared in the prescriptions to the total of 127 prescriptions that have been used for
} treating PD 
Cnidii Rhizoma, Cinnamomi Ramulus, and Atractylodis Rhizoma, the chi-square test was used; Yate's continuity correction was used for while the Fisher's exact test was used for Aconiti Lateralis Radix Preparata and Arisaematis Rhizoma, while the Fisher's exact test was used for Araliae Continentalis Radix, Achyranthis Radix, Ephedrae Herba, Aconiti Tuber, Chaenomelis Fructus, Myrrha, Gastrodiae Rhizoma, Sinomeni Caulis et Rhizoma, Batryticatus Bombyx, and Aconiti Kusnezoffii Tuber.

Osterici seu Notopterygii Radix et Rhizoma $\left(\chi^{2}\right.$ $=84.608)$, Saposhnikoviae Radix $\left(\chi^{2}=61.407\right)$, Atractylodis Rhizoma $\left(\chi^{2}=28.258\right)$, Cnidii Rhizoma $\left(\chi^{2}=15.524\right)$, Araliae Continentalis Radix $(\mathrm{p}<$ $0.0001)$, and Chaenomelis Fructus $(\mathrm{p}<0.0001)$ were identified specifically for $\mathrm{PD}$, as their chi-square values were very high or p-values were very low.

The remaining 23 herbs were statistically rejected, as there was no significant difference in the results of the chi-square test performed for the herbs in the two groups, even though the frequency of appearance in the prescriptions was high.

\section{Proper Dose for Medicinal Herbs}

Among the 17 herbs selected above, Osterici seu Notopterygii Radix et Rhizoma, Aconiti Lateralis Radix Preparata, Arisaematis Rhizoma, Achyranthis Radix, Chaenomelis Fructus, Sinomeni Caulis et Rhizoma, and Batryticatus Bombyx showed a normal distribution on the Shapiro-Wilk test; hence, they were further analysed using the t-test. The Wilcoxon test was used for Saposhnikoviae Radix, Cnidii Rhizoma, Cinnamomi Ramulus,
Araliae Continentalis Radix, Atractylodis Rhizoma, and Ephedrae Herba as these herbs did not follow a normal distribution. There was no significant difference in the dose of medicinal herbs used in the two groups $(p<0.05)$. Aconiti Tuber, Myrrha, Gastrodiae Rhizoma, and Aconiti Kusnezoffii Tuber were excluded from the analysis because there was insufficient data to investigate the appropriate dose of these herbs.

In cases of Aconiti Tuber, Myrrha, and Gastrodiae Rhizoma, the mean and median values of all prescriptions were obtained and are described in Table 3. Aconiti Kusnezoffii Tuber was excluded because all prescriptions for this herb were in the form of a solid. For numerical analysis, the 'mean value of dose of each herb used in the two groups for daily dose' and 'mean, median, minimum, and maximum value of dose of each herb used in all prescriptions for daily dose' were calculated and are shown in Table 3.

\section{Discussion}

This research conducted a process of statistical analysis on Donguibogam, the traditional literature of Korean medicine for finding herbal candidates deemed effective for PD to identify a list of candidate herbs.

Based on the idea that herbs prescribed with the highest frequency are more likely to be effective, 40 herbs that made up more than $5 \%$ of the total prescriptions used for treating PD were searched and selected for analysis. Glycyrrhiza uralensis, Saposhnikoviae Radix, Osterici seu Notopterygii Radix et Rhizoma, Cnidii Rhizoma, Angelicae Gigantis Radix, Paeoniae Radix, and 
Ginseng Radix were prescribed more than 25 prescriptions among the 127 total prescriptions, being the most frequently prescribed herbs in the list and they could be considered candidate substances. However, when it comes to experimental research trying to find candidate herbs more likely to be effective, additional information including statistical values would increase the success rate of the research. In addition, comparatively less frequently prescribed herbs still could be on the list of candidate substances if there is additional information.

In the first analysis, the chi-square test was used to verify the difference of prescription frequency of herbs in the two groups and 17 herbs were selected for potentially treating PD.
This was derived from the fact that those herbs were more statistically significant in the group of prescriptions for $\mathrm{PD}$ than in the prescription group not for PD.

Among them, Saposhnikoviae Radix, Osterici seu Notopterygii Radix et Rhizoma, Cnidii Rhizoma, and Cinnamomi Ramulus were included in the top 10 frequently used herbs. The four herbs are more reliable to be candidate substances deemed effective for PD because we found out the fact through the statistical tests that the herbs have been more specifically used for PD symptoms.

A notable part of this research is that Araliae Continentalis Radix, Achyranthis Radix, Chaenomelis Fructus, Sinomeni Caulis et Rhizoma, Aconiti

Table 3. Mean and median value of daily dose of 17 herbs deemed potentially effective for Parkinson's Disease.

\begin{tabular}{|c|c|c|c|c|c|c|c|}
\hline \multirow{3}{*}{$\begin{array}{l}\text { Botanomical name } \\
\text { Saposhnikoviae Radix }\end{array}$} & \multirow{3}{*}{$\begin{array}{l}\text { Korean name } \\
\text { Bangpung }\end{array}$} & \multirow{2}{*}{\multicolumn{2}{|c|}{$\begin{array}{c}\mathrm{PD}^{\dagger} \quad \text { Non- } \mathrm{PD}^{\ddagger} \\
\text { Mean[g] }\end{array}$}} & \multicolumn{4}{|c|}{ Total } \\
\hline & & & & \multirow{2}{*}{$\begin{array}{c}\text { Mean } \\
5.84\end{array}$} & \multirow{2}{*}{$\begin{array}{c}\text { Median } \\
5.26\end{array}$} & \multirow{2}{*}{$\begin{array}{l}\text { Min } \\
0.75\end{array}$} & \multirow{2}{*}{$\frac{\operatorname{Max}}{30.00}$} \\
\hline & & 5.88 & 5.46 & & & & \\
\hline Osterici seu Notopterygii Radix et Rhizoma & Kangwhal & 6.50 & 7.16 & 6.60 & 5.62 & 1.50 & 15.00 \\
\hline Cnidii Rhizoma & Cheongung & 6.76 & 5.96 & 6.72 & 6.00 & 1.25 & 37.50 \\
\hline Cinnamomi Ramulus & Gyeji & 6.92 & 8.46 & 7.06 & 5.26 & 0.75 & 30.00 \\
\hline Atractylodis Rhizoma & Changchul & 8.38 & 8.48 & 8.46 & 7.50 & 1.88 & 45.00 \\
\hline Aconiti Lateralis Radix Preparata & Buja & 9.12 & 7.98 & 8.96 & 7.50 & 1.50 & 22.50 \\
\hline Arisaematis Rhizoma & Namseong & 7.76 & 13.12 & 7.98 & 7.50 & 1.88 & 30.00 \\
\hline Araliae Continentalis Radix & Dokwhal & 5.18 & 5.42 & 5.22 & 4.50 & 1.50 & 15.00 \\
\hline Achyranthis Radix & Wooseul & 4.80 & 4.52 & 4.76 & 3.76 & 2.25 & 15.00 \\
\hline Ephedrae Herba & Mahuang & 8.90 & 8.10 & 8.84 & 7.50 & 1.50 & 22.50 \\
\hline Aconiti Tuber & Cheono & & 6.26 & 5.86 & 7.50 & 0.75 & 15.00 \\
\hline Chaenomelis Fructus & Mogwa & 7.36 & 5.62 & 7.24 & 6.38 & 1.88 & 30.00 \\
\hline Myrrha & Molyak & & 5.50 & 5.48 & 4.50 & 2.25 & 15.00 \\
\hline Gastrodiae Rhizoma & Cheonma & & 5.56 & 5.44 & 5.26 & 0.75 & 15.00 \\
\hline Sinomeni Caulis et Rhizoma & Bang-gi & 5.52 & 7.38 & 5.80 & 5.26 & 1.88 & 15.00 \\
\hline Batryticatus Bombyx & Baekkangjam & 5.50 & 6.00 & 5.58 & 5.62 & 2.25 & 7.50 \\
\hline
\end{tabular}


Tuber, and Aconiti Kusnezoffii Tuber were found to be relatively infrequently prescribed herbs but eventually selected to be deemed effective herbs. If the prescription frequency was only considered, they would not have been suitable candidate substances. However, the herbs were tested using Fisher's exact test and found to be more statistically significantly used in the group of prescriptions for $\mathrm{PD}$ than in the group of prescriptions not for $\mathrm{PD}$, which means they have been more specifically used for PD symptoms. (p-value $<0.001)$ In this way, additional information that which herbs are specific to which disease gives opportunities to embrace novel herbs into the list of candidate substances that otherwise would have been unthinkable.

It was possible to determine the priority order among selected herbs based on the chi-square value or the $p$-value. The higher the chi-square value and the lower the p-value, the more pronounced the difference between the two groups. The priority order of Saposhnikoviae Radix and Osterici seu Notopterygii Radix et Rhizoma was calculated based on chi-square values and that of Araliae Continentalis Radix and Chaenomelis Fructus was calculated based on p-values as these herbs were tested using Fisher's exact test.

Among the herbs on the list, 11 herbs were previously researched. According to the systematic review by $\mathrm{Su}$ Yeon Lim et al., Batryticatus Bombyx, Gastrodiae Rhizoma, Achyranthis Radix, Aconiti Tuber, and Arisaematis Rhizoma have been prescribed for $\mathrm{PD}^{19)}$. Xin-Chun Jin et al. reported in the systematic review that Cnidii Rhizoma was used as a single agent and a prescription included both Batryticatus Bombyx and Gastrodiae Rhizoma for treating $\mathrm{PD}^{20)}$. Hwan Soo Joo et al. reported that Gastrodiae Rhizoma was used as a single agent and a newly developed prescription for PD included Batryticatus Bombyx, Saposhnikoviae Radix, Cinnamomi Ramulus, and Chaenomelis Fructus as ingredients ${ }^{21)}$. Previous studies reported that Araliae Continentalis Radix and Cinnamomi Ramulus could be utilised for treating $\mathrm{PD}^{22,23)}$.

Saposhnikoviae Radix, Cnidii Rhizoma, Araliae Continentalis Radix, and Atractylodis Rhizoma are also on a list of candidate substances for treating PD suggested by previous text mining research on rigidity with Donguibogam ${ }^{14)}$. In contrast to the past studies, the authors paid close attention to the prescription frequency of herbs for PD and other diseases and determined the listed herbs have been prescribed specifically for PD. Also, this research broadened the for the analysis while the previous research focused on rigidity.

Therefore, this research suggests Osterici seu Notopterygii Radix et Rhizoma, Ephedrae Herba, Aconiti Tuber, Myrrha, Sinomeni Caulis et Rhizoma, and Aconiti Kusnezoffii Tuber as novel candidate substances for treating PD. The six herbs have been researched for their clinical effectiveness for other diseases. However, never has there been any research for PD conducted with the six herbs.

According to the recent studies, Osterici seu Notopterygii Radix et Rhizomahas the effect of treating immunological diseases such as allergic reactions ${ }^{24)}$, Aconiti Tuber could improve low levels of serotonin in the medulla ${ }^{25)}$, Ephedrae 
Herba exhibits inhibitory effects on neuroinflammation ${ }^{26)}$ Sinomeni Caulis et Rhizoma ameliorates neuropsychological problems including insomnia, depression, and inflammation by affecting GABA, norepinephrine, 5-hydroxytryptamine ${ }^{27,28,29)}$ and Myrrha has anti-neuroinflammation effect ${ }^{30}$. These findings that these herbs have neurological, immunological efficacies imply the possibility that the drugs may also be effective for treating PD.

The second analysis was designed and performed with a hypothesis that medicinal herbs deemed effective for PD had been prescribed with a larger dose for PD. However, there was no significant difference in the dose of medicinal herbs used in the two groups. Therefore, when determining the appropriate dose of medicinal herbs, it is not necessary to focus on difference between the two groups, but it is reasonable to refer to the overall mean or median values.

Since this study selected medicinal herbs from Donguibogam, the original literature, its limitation is that it requires experimental verification. We could not confirm whether the selected herbs are effective in treating the PD symptoms, and therefore future experimental research is necessary to authenticate their effectiveness.

This study aims to find the herbs solely used for PD symptoms, not every single herbal drug effective for PD treatment. Thus, herbs used not only for PD, but also other diseases have been excluded from the list. The authors started this research with the premise that herbs specifically prescribed with high frequency are more likely to be effective for a specific disease. Therefore, the limitation is that the assumption of this study is not always applicable in all cases. However, this analysis may provide a new perspective on finding novel candidate herbs deemed effective for PD. It also takes a short period, especially 3-4 weeks in this research. As statistical process of analysis could be utilised for the development of future novel drugs for other diseases, the authors standardisation and utilisation of this process.

\section{Conclusions}

Saposhnikoviae Radix, Osterici seu Notopterygii Radix et Rhizoma, Cnidii Rhizoma, Cinnamomi Ramulus, Atractylodis Rhizoma, Aconiti Lateralis Radix Preparata, Arisaematis Rhizoma, Araliae Continentalis Radix, Achyranthis Radix, Ephedrae Herba, Aconiti Tuber, Chaenomelis Fructus, Myrrha, Gastrodiae Rhizoma, Sinomeni Caulis et Rhizoma, Batryticatus Bombyx, and Aconiti Kusnezoffii Tuber were selected as herbs potentially effective for treating PD. Since there was no significant difference in the dose of individual herbs used in the two groups for a daily dose, we speculated that the average dose of the entire prescription would be appropriate for each herb.

Furthermore, this study presented quantitative statistical evidence for obtaining a list of medicinal herbs and appropriate dose for each herb useful for treating PD by applying the chi-square test, t-test, and Wilcoxon test to Donguibogam, the original literature.

\section{Acknowledgment}

This work was supported by the Health Fellowship Foundation. 


\section{References}

1. Kalia L.V., Lang A.E. (2015). Parkinson's disease. Lancet, 386(9996), 896-912. http://doi.org/10. 1016/S0140-6736(14)61393-3.

2. Carranza M., Snyder M.R., Shaw J.D., Zesiewicz T.A. (2013). Parkinson's Disease: A Guide to Medical Treatment. (1st ed.). Italy: SEEd Medical Publishers.

3. Dexter D.T., Jenner P. (2013). Parkinson disease: from pathology to molecular disease mechanisms. Free Radic Biol Med, 62, 132 -144. http://doi.org/10.1016/j.freeradbiomed. 2013.01.018

4. Johnson K.E. (2015). Approach to the patient with Parkinson disease. Prim Care, 42(2), 205-215. http://doi.org/10.1016/j.pop.2015.01.005.

5. Ossig C., Reichmann H. (2015). Treatment strategies in early and advanced Parkinson disease. Neurol Clin, 33(1), 19-37. http://doi.org/ 10.1016/j.ncl.2014.09.009.

6. Yang S.B., Kim Y.J., Lee H.M., Lee S.H., Cho S.Y., Park J.M., et al. (2017). Effects of Korean medicine on postural instability and gait difficulty in patient with Parkinsonism: Retrospective study. J Korean Med, 38(3), 96-102. http://dx.doi.org/10.13048/jkm.17028.

7. Beudel M., Brown P. (2016). Adaptive deep brain stimulation in Parkinson's disease. Parkinsonism Relat Disord, 22(1), 123-126. http://doi.org/10.1016/j.parkreldis.2015.09.028.

8. Amro M.S., Teoh S.L., Norzana A.G., Srijit D. (2018). The potential role of herbal products in the treatment of Parkinson's disease. Clin Ter, 169(1), 23-33. http://doi.org/10.7417/T. 2018.2050.
9. Liu C., Huang X., Qiu S., Chen W., Li W., Zhang H., et al. (2019). Chinese Herbal Complex 'Bu Shen Jie Du Fang' (BSJDF) Modulated Autophagy in an MPP +-Induced Cell Model of Parkinson's Disease. Evid Based Complement Alternat Med, 2019, 8920813. http://doi.org/10.1155/2019/8920813.

10. Sun C., Wang D., Jiang W., Liao W., Gao P., Pan W., et al. (2017). Quantitative Evaluation of Chinese Herb Medicine in the Treatment of Sialorrhea and Frequent Nighttime Urination in Patients with Parkinson's Disease. Evid Based Complement Alternat Med, 2017, 3045260. http://doi.org/10.1155/2017/3045260.

11. Guideline center for Korean medicine. (2020). Korean Medicine Clinical Practice Guideline for Parkinson's disease. National Institute for Korean Medicine Development.

12. Song B.K., Won J.H., Kim S.C. (2016). Historical Medical Value of Donguibogam. Journal of Pharmacopuncture, 19(1), 16-20. http://doi.org/10.3831/KPI.2016.19.002.

13. Memory of the World. Donguibogam: Principles and Practice of Eastern Medicine. UNESCO; Paris. 2009. [Accessed 16 August 2021]. Available from: URL: http://www.unesco. org/new/en/communication-and-information/ flagship-project-activities/memory-of-the-world/ register/full-list-of-registered-heritage/registered -heritage-page-2/donguibogam-principles-and -practice-of-eastern-medicine.

14. Park S.H., Hwang M.S., Park H.J., Shin H.K., Baek J.U., Choi B.T. (2018). Herbal Prescriptions and Medicinal Herbs for Parkinson-Related Rigidity in Korean Medicine: Identification of Candidates Using 
Text Mining. J Altern Complement Med, 24(7), 733-740. http://doi.org/10.1089/acm. 2017.0387.

15. Jeong H.S., Kim H.R., Kim S.Y., Yim T.B., Jin C., Kwon S.W., et al. (2020). Clinical characteristics of pain in patients with Parkinson's disease who have visited a Korean medical hospital: A retrospective chart review. J Korean Med, 41(2), 23-33. http://dx.doi.org/10.13048/jkm.20012.

16. Hwang M.S., Park H.J., Kim S.W., Baek J.U. (2018). Research on prescription candidates for Parkinson's disease in ${ }^{\circledR}$ Dongeuibogam $\sqrt{\unlhd}$. Herbal Formula Science, 26(1), 65-80. https://doi.org/10.14374/HFS.2018.26.1.65.

17. Kellar S.P., Kelvin E. (2012). Munro's statistical methods for health care research. (6th ed.). Pennsylvania, Philadelphia: Lippincott Williams \& Wilkins.

18. Armitage P., Berry G., Matthews J. N. S. (2008). Statistical Methods in Medical Research. (4th ed.). Hoboken, N.J: John Wiley \& Sons. https://doi.org/10.1002/9780470773666

19. Lim S.Y., Kim H.R., Choi Y.S., Lee I. (2016). Review of Current Clinical Studies for Herbal Medicine of Parkinson's Disease in Traditional Chinese Medicine. J Physiol \& Pathol Korean Med, 30(5), 327-337. http://doi.org/ 10.15188/kjopp.2016.10.30.5.327.

20. Jin X.C., Zhang L., Wang Y., Cai H.B., Bao X.J., Jin Y.Y., et al. (2019). An Overview of Systematic Reviews of Chinese Herbal Medicine for Parkinson's Disease. Front Pharmacol, 10,155. https://doi.org/10.3389/ fphar.2019.00155.

21. Joo H.S., Yu O.C., Han C., Yang K.J., Lee
S.Y., Moon H.Y. (2017). A Review on Experimental Studies of Parkinson's Disease in Korean Medical Journals. J of Oriental Neuropsychiatry, 28(3), 145-156. https://doi.org/ 10.7231/jon.2017.28.3.145

22. Khasnavis S., Pahan K. (2014). Cinnamon treatment upregulates neuroprotective proteins Parkin and DJ-1 and protects dopaminergic neurons in a mouse model of Parkinson's disease. J Neuroimmune Pharmacol, 9(4), 569-81. http://doi.org/10.1007/s11481-014-9552-2.

23. Lee S.H., Lee J.H., Oh E.Y., Kim G.Y., Choi B.T., Kim C., et al. (2013). Ethanol extract of Cnidium officinale exhibits anti-inflammatory effects in BV2 microglial cells by suppressing $\mathrm{NF}-\kappa \mathrm{B}$ nuclear translocation and the activation of the PI3K/Akt signaling pathway. Int $\mathrm{J}$ Mol Med, 32(4), 876-82. http://doi.org/10.3892/ ijmm.2013.1447.

24. Jung H.W., Jung J.K., Park Y.K. (2011). Antiallergic effect of Ostericum koreanum root extract on ovalbumin-induced allergic rhinitis mouse model and mast cells. Asian Pac J Allergy Immunol, 29(4), 338-48.

25. Ikeda Y., Oyama T., Taki M. (1994). Effect of processed Aconiti tuber on catecholamine and indoleamine contents in brain in rats. Acta Anaesthesiol Belg, 45(3), 113-8.

26. Park S.Y., Yi E.H., Kim Y., Park G. (2019). Anti-neuroinflammatory effects of Ephedra sinica Stapf extract-capped gold nanoparticles in microglia. Int $\mathrm{J}$ Nanomedicine, 14, 2861 -2877. http://doi.org/10.2147/IJN.S195218.

27. Kim T.W., Han J.M., Han Y.K., Chung H. (2018). Anti-inflammatory Effects of Sinomenium Acutum Extract On Endotoxin-induced 
Uveitis in Lewis Rats. Int J Med Sci, 15(8), 758-764. http://doi.org/10.7150/ijms.24834.

28. Liu S., Xu S., Wang Z., Guo Y., Pan W., Shen Z. (2018). Anti-Depressant-Like Effect of Sinomenine on Chronic Unpredictable Mild Stress-Induced Depression in a Mouse Model. Med Sci Monit, 24, 7646-7653. http://doi.org/10.12659/MSM.908422.

29. Yoo J.H., Ha T.W., Hong J.T., Oh K.W. (2017). Sinomenine, an Alkaloid Derived from Sinomenium acutum Potentiates Pentobarbital -Induced Sleep Behaviors and Non-Rapid Eye Movement (NREM) Sleep in Rodents. Biomol Ther (Seoul), 25(6), 586-592. http://doi.org/10.4062/biomolther.2017.157.

30. Miao XD, Zheng LJ, Zhao ZZ, Su SL, Zhu Y, Guo JM, Shang EX, et al. (2019). Protective
Effect and Mechanism of Boswellic Acid and Myrrha Sesquiterpenes with Different Proportions of Compatibility on Neuroinflammation by LPS-Induced BV2 Cells Combined with Network Pharmacology. Molecules, 24(21),3946. http://doi.org/10.3390/ molecules24213946.

\section{ORCID}

Hyo Won Bae https://orcid.org/0000-0002-5043-6748

Tae Wook Lee https://orcid.org/0000-0003-4882-2233

Byung Tae Choi https://orcid.org/0000-0002-5965-4346

Hwa Kyoung Shin https://orcid.org/0000-0002-8061-6782

Young Ju Yun https://orcid.org/0000-0002-4598-2322 